University of Nebraska - Lincoln

DigitalCommons@University of Nebraska - Lincoln

\title{
Risk propensity and health risk behaviors in U.S. army soldiers with and without psychological disturbances across the deployment cycle
}

\author{
Amanda M. Kelley \\ United States Army Aeromedical Research Laboratory, amanda.m.kelley@us.army.mil \\ Jeremy R. Athy \\ United States Army Aeromedical Research Laboratory \\ Timothy H. Cho \\ United States Army Aeromedical Research Laboratory \\ Bradley Erickson \\ United States Army Aeromedical Research Laboratory \\ Melody King \\ United States Army Aeromedical Research Laboratory \\ See next page for additional authors
}

Follow this and additional works at: https://digitalcommons.unl.edu/usarmyresearch

Kelley, Amanda M.; Athy, Jeremy R.; Cho, Timothy H.; Erickson, Bradley; King, Melody; and Cruz, Pedro, "Risk propensity and health risk behaviors in U.S. army soldiers with and without psychological disturbances across the deployment cycle" (2012). US Army Research. 200.

https://digitalcommons.unl.edu/usarmyresearch/200

This Article is brought to you for free and open access by the U.S. Department of Defense at DigitalCommons@University of Nebraska - Lincoln. It has been accepted for inclusion in US Army Research by an authorized administrator of DigitalCommons@University of Nebraska - Lincoln. 


\section{Authors}

Amanda M. Kelley, Jeremy R. Athy, Timothy H. Cho, Bradley Erickson, Melody King, and Pedro Cruz 


\title{
Risk propensity and health risk behaviors in U.S. army soldiers with and without psychological disturbances across the deployment cycle
}

\author{
Amanda M. Kelley*, Jeremy R. Athy, Timothy H. Cho, Bradley Erickson, Melody King, Pedro Cruz \\ United States Army Aeromedical Research Laboratory, Building 6901, Farrel Rd., P.O. Box 620577, Fort Rucker, AL 36362-0577, USA
}

\section{A R T I C L E I N F O}

\section{Article history:}

Received 3 October 2011

Received in revised form

10 January 2012

Accepted 12 January 2012

\section{Keywords:}

Risk propensity

Combat deployment

Health risk behaviors

\begin{abstract}
A B S T R A C T
Anecdotal and preliminary evidence suggests that Soldiers returning from a combat deployment engage in an increased number of health risk behaviors. Three potential factors driving this change were examined in this study; posttraumatic stress disorder (PTSD), concussion and traumatic brain injury (TBI), and perceived invincibility. We studied members of a combat arms brigade one month prior to a deployment to Iraq and approximately one month after their return $(N=319)$. Participants anonymously completed surveys characterizing attitudes about risk, risk propensity, invincibility, engagement in health risk behaviors, and personality. Using standardized screening instruments, participants were categorized with respect to PTSD and probable TBI. Results suggest that Soldiers engage in more alcohol use and reckless driving behaviors post-deployment. These changes were exaggerated in those who screened positive for PTSD. Perception of one's invincibility and survival skills increased postdeployment thus suggesting that participants felt less susceptible to adverse consequences and more adept at surviving dangerous situations. This study provides documentation of the pattern of health behavior in Soldiers engaged in the deployment cycle. Our findings suggest increases in the number of risks Soldiers' engage in post-deployment are not limited to those with PTSD symptomtotology. This study has implications for not only adjustment to life post-deployment at the individual level but also operational readiness.
\end{abstract}

Published by Elsevier Ltd.
Over one million service members have deployed to support Operation Iraqi Freedom (OIF) and Operation Enduring Freedom (OEF). The conditions under which these Soldiers carry out their missions are both physically and psychologically stressful. Soldiers returning from an overseas deployment such as OIF or OEF are vulnerable to the effects of combat stress. The duress of combat does not selectively discriminate, and the mental and physical exhaustion that follows takes its toll on both the inexperienced and seasoned veteran alike. Despite sound military training and advanced technology, personal resilience is not equal for every Soldier who endures combat. Soldiers, being human, instinctively safeguard the basic need for self-preservation when threatened, and each experience is uniquely processed by the individual over the course of deployment.

Combat experience is associated with mental health problems (Hoge et al., 2004; Killgore et al., 2008; Sharkansky et al., 2000). Estimates indicate $14 \%$ of Soldiers returning from OIF and OEF experience posttraumatic stress disorder (PTSD), 14\% experience

\footnotetext{
* Corresponding author. Tel.: +1 334255 6859; fax: +1 3342556993 .

E-mail address: amanda.m.kelley@us.army.mil (A.M. Kelley).
}

major depression, and 19.5\% have sustained a mild traumatic brain injury (mTBI; Tanielian and Jaycox, 2008). Of those who have suffered an mTBI during deployment, 35\% experience persistent symptoms or postconcussive syndrome (PCS; Schneiderman et al., 2008). The full extent of the psychological effects of ongoing military operations is unknown.

One aspect of the psychosocial effect of combat is the reported increase in risky behaviors exhibited by Soldiers post-deployment. Killgore et al. (2008) found that Soldiers who experienced more severe and intense combat were at a slightly greater risk of engaging in high risk behaviors post-deployment. While this finding was statistically significant, the effect size was small, indicating that combat exposure only accounts for a small proportion of the variance with respect to risky behavior. It is unclear what other factors may influence risk propensity following combat exposure. Likewise, in a recent study, Thomsen et al. (2011) found that when surveyed, service members who had deployed reported engaging in more risky behaviors than those who had never deployed.

The effects of prolonged exposure to emotional stressors (e.g., combat-related) may impact regions of the brain (specifically the limbic system) in such a way that Soldiers may have difficulty adjusting to a non-wartime environment upon returning from 
a deployment (Killgore et al., 2008). Soldiers with PTSD have diminished activity in the limbic system and regions of the prefrontal cortex, which might suggest low basal arousal levels (Molina et al., 2007). Additionally, young adults with a history of head injury exhibit a greater interest in risky behaviors (O'Jile et al., 2004). One potential mechanism driving similar behavior postdeployment is the impact of psychological combat trauma-particularly perceived "near-death" experiences-on one's beliefs and behaviors related to life and death. These changes in beliefs and behaviors are not a manifestation of any mental illness but may function as a coping mechanism (Bell et al., 2001). Whereas the Thomsen et al. (2011) recent cross-sectional study reported changes in behavior from pre- to post-deployment, a longitudinal study will provide stronger evidence to our understanding of the relationships between deployment and adverse health outcomes.

The objective of this study was two-fold: 1) to evaluate risk propensity and risk behavior in Soldiers as a function of deployment using a within-subjects, longitudinal design (i.e., the same group of Soldiers was tested pre- and post-deployment), 2) to evaluate the impact of PTSD and TBI on attitudes about risk and engagement in risky behaviors. The implications of the study results with respect to promotion of health and prevention of injury are discussed.

\section{Method}

\subsection{Participants}

Volunteers were recruited from a combat battalion (approximately 800 Soldiers) of a U.S. Army Infantry Division. Approximately 30 days prior to a 12-month deployment to Iraq (October 2009-September 2010), 492 Soldiers completed the task battery (62\% response rate); 387 of them returned to complete the task battery again, approximately one month post-deployment $(79 \%$ retention rate). Permanent change of station, leave status, medical evacuation, or behavioral problems prior to the testing window precluded some Soldiers' post-deployment testing thus information about these individuals were unavailable. We were able to confidently match 319 pre-deployment and post-deployment datasets. Specifically, to preserve anonymity while matching a participant's dataset (pre-deployment and post-deployment data), an unidentifiable code was used to link the data. This code was generated using information provided by the participant. Thus, errors in entry yielded some unique codes that could not be matched (68 total unmatched). This study was reviewed and approved by the U.S. Army Medical Research and Materiel Command Institutional Review Board (USAMRMC IRB) and conducted in compliance with federal regulations regarding protection of human subjects in research. Since participants were allowed to skip questions they did not feel comfortable answering, the number of participants available for analysis varied by measure. Specifically, if a participant skipped a question on a measure, the score on the validated measure could not be computed accurately, thus the participant was excluded from that measure. To be included in the analysis, participants had to complete $75 \%$ of the measures. Therefore, of the 319 matched datasets, 262 datasets were eligible for analysis.

To assess the representativeness of our sample, the demographic data was compared by means of the Defense Medical Surveillance System to those of active-duty Army personnel deployed to OIF and OEF (Ruberton and Brundage, 2002).

\subsection{Surveys and outcome variables}

Participants were categorized into one of four groups based on responses and scores from the 17-item PTSD Checklist-Military version (Bliese et al., 2008; Kang et al., 2003) and the Brief TBI Screen (Schwab et al., 2007) both of which were administered postdeployment. The PTSD group consisted of participants who screened positive as determined by guidelines published by the National Center for PTSD. The TBI group consisted of participants who screened positive for a probable TBI. The PTSD $w / T B I$ group consisted of those who screened positive for both, and the control group was comprised of those who screened negative for both.

The pre-deployment test battery consisted of both neuropsychological assessments and questionnaires which were presented in random order. The questionnaires included a measure of personality - the Zuckerman-Kuhlman Personality Questionnaire (five factors: sociability, neuroticism, activity, impulsive sensation seeking, aggression; Zuckerman et al., 1993); a measure of emotion regulation - the Emotion Regulation Questionnaire (two factors: cognitive reappraisal and emotional suppression; Gross and John, 2003); baseline measures of depression and anxiety levels Beck's Depression Inventory (Beck and Steer, 1984; Beck et al., 1988b) and Beck's Anxiety Inventory (Beck et al., 1988a; Hewitt and Norton, 1993); an inventory of health risk behaviors including questions from the alcohol use disorders identification test (Saunders et al., 1993), the Centers for Disease Control and Prevention's youth risk behavior survey regarding tobacco use (Center for Disease Control and Prevention, 2009), and the Driving Behavior Questionnaire (Parker et al., 1995) as well as a question regarding Army Substance Abuse Program (ASAP) referral; a measure of risk propensity - the Evaluation of Risks Questionnaire (EVAR-English version; three factors: need-for-control, selfconfidence, risk/thrill seeking; Sicard et al., 2001; Killgore et al., 2006); and a measure of perceived invincibility, the Invincibility Belief Index (IBI; total invincibility belief score and three factors: adroitness, impunity, boldness; Killgore et al., 2010). Additionally, participants completed a measure of behavioral risk-taking - the Balloon Analog Risk Task (Lejuez et al., 2002); and a behavioral decision making task incorporating uncertainty, reward, and punishment -the Iowa Gambling Task (Bechara et al., 1997, 2001, 2000). Measures of personality and self-regulatory competence were included given the relationship between these individual differences and risky behavior (respectively, Zuckerman and Kuhlman, 2000; Byrnes, 2005).

The post-deployment test battery included the same instruments and tasks as the pre-deployment test battery with the addition of the 7-item combat exposure scale (Keane et al., 1989) and the deployment concerns sub-scale of the deployment risk and resilience inventory (King et al., 2003, 2006). These items characterized the participants' actual experiences and perceptions of the environment and threats while deployed.

\subsection{Quality control and statistical design}

All responses were recorded electronically using the psychological experiment software E-prime (version 2.0) and exported into Microsoft Office 2007 Excel for organization. Any questions that were skipped were identified in the dataset. As the responses were recorded electronically, the data file included the participants' reaction time to give a response which was recorded from the onset of the presentation of a question. Any reaction times that were less than a reasonable amount of time (which varied by instrument) to have read the question or observe the screen (whether by error or intentional) were marked as skipped questions in the dataset. All data were then imported to SPSS software (version 17.0) and analyzed using mixed model 4 (group: PTSD, TBI, PTSD w/TBI, control) $\times 2$ (combat deployment: pre-, post-) analyses of variance (ANOVAs) and post-hoc tests. Given the unequal sample sizes between groups, Levene's test of homogeneity of variance was 
conducted. Additionally, a between-subjects ANOVA was conducted to compare the 4 groups' responses on the deployment concerns and combat experiences surveys. Finally, a multiple linear regression was conducted to evaluate potential predictors of probable PTSD (e.g., pre-deployment psychological disturbance).

\section{Results}

The sample was primarily composed of U.S. Army Soldiers with an infantry military occupational specialty (MOS). The top three most frequently reported MOSs were Infantry (32.6\%), Armor Crewman (17.6\%), and Combat Medic (5.6\%). Although the demographic characteristics of our sample were largely similar to the reference group obtained from the Defense Medical Surveillance System, the rank distributions and age were slightly lower in our sample due to an undersampling of officers (Table 1). Females were also underrepresented in our sample which is to be expected given that we sampled from an infantry battalion.

A one-way ANOVA indicated significant differences between groups for the combat experiences survey scores such the control group scored lower than the other 3 groups, $F(3,242)=7.031$, $p<0.001$ (Fig. 1). Similarly, a one-way ANOVA showed that PTSD and PTSD $w / T B I$ groups scored higher on the deployment concerns survey than control and TBI groups, $F(3,243)=14.998, p<0.001$ (Fig. 2).

Post-deployment scores of aggression, activity, neuroticism, perceived invincibility, adroitness, risk/thrill seeking, selfconfidence, depression symptoms, frequency of drinking episodes, and referrals to the Army Substance Abuse Program (ASAP) increased across all participants. Participants' scores of

\section{Table 1}

Demographic characteristics of study groups of soldiers compared across conditions; frequency (percent).

\begin{tabular}{|c|c|c|}
\hline Characteristic & $\begin{array}{l}\text { Reference } \\
\text { group } \\
(N=113,582)\end{array}$ & $\begin{array}{l}\text { Army study } \\
\text { sample } \\
(N=262)\end{array}$ \\
\hline \multicolumn{3}{|l|}{ Age } \\
\hline $18-24 \mathrm{yr}$ & $45,427(40)$ & $139(53.6)$ \\
\hline $25-29 \mathrm{yr}$ & $29,172(25.7)$ & $70(27.0)$ \\
\hline $30-39 \mathrm{yr}$ & $29,245(25.7)$ & $38(14.7)$ \\
\hline $40 \mathrm{yr}$ or older & $9738(8.6)$ & $12(4.6)$ \\
\hline Missing values & & 3 \\
\hline \multicolumn{3}{|l|}{ Sex } \\
\hline Male & $101,786(89.6)$ & $258(99.2)$ \\
\hline Female & $11,796(10.4)$ & $2(0.7)$ \\
\hline Missing values & & 2 \\
\hline \multicolumn{3}{|l|}{ Race or ethnic group } \\
\hline Caucasian & $82,193(72.4)$ & $187(71.4)$ \\
\hline African American & $20,819(18.3)$ & $31(11.8)$ \\
\hline Hispanic & $12,617(11.1)$ & $32(12.2)$ \\
\hline Other & $6006(4.2)$ & $12(4.6)$ \\
\hline \multicolumn{3}{|l|}{ Education } \\
\hline No high-school diploma & $935(0.7)$ & $22(8.4)$ \\
\hline HS diploma or some college & $101,114(71.2)$ & $220(83.9)$ \\
\hline College graduate & $16,136(11.4)$ & $20(7.6)$ \\
\hline \multicolumn{3}{|l|}{ Military grade } \\
\hline \multicolumn{3}{|l|}{ Enlisted personnel } \\
\hline E1-E4 & $70,291(49.5)$ & $166(63.4)$ \\
\hline E5-E6 & $37,648(26.5)$ & $77(29.3)$ \\
\hline E7-E9 & $12,292(8.7)$ & $12(4.6)$ \\
\hline Officer & $21,805(15.4)$ & $7(2.6)$ \\
\hline \multicolumn{3}{|l|}{ Prior combat experience } \\
\hline Yes & Not available & $127(48.5)$ \\
\hline No & Not available & $135(51.5)$ \\
\hline
\end{tabular}

Note. Military grades of E1-E4 represent lower enlisted, E5-E6 represent junior noncommissioned officers (NCOs), and E7-E9 represent senior NCOs. Missing values are not represented, as some participants chose not to answer all questions. Percentages may not sum to 100 due to rounding. Reference group includes active-duty only Army personnel deployed to OIF in 2010.

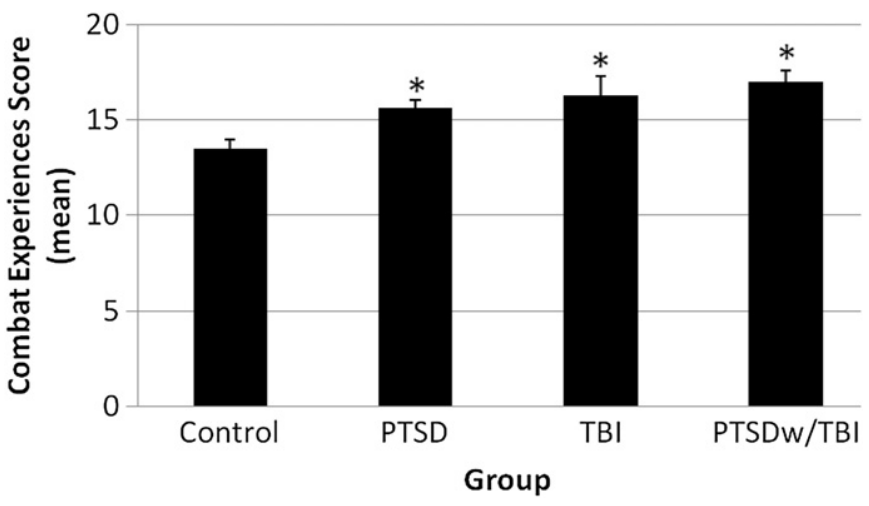

Fig. 1. Bar graph of mean combat experiences score by group. Error bars represent standard error of the mean. * indicates a significant difference from control group at $p<0.05$.

sociability and need for control decreased post-deployment. Smokers reported smoking less post-deployment and of those who reported riding a motorcycle, helmet-use decreased postdeployment (Table 2). There were no significant main effects or interactions for the following measures: Zuckerman-Kuhlman Personality Questionnaire (impulsive sensation seeking subscale), Emotion Regulation Questionnaire, Invincibility Belief Index (impunity and boldness subscales), Balloon Analog Risk Task, and Iowa Gambling Task.

Overall, the results showed that the PTSD and PTSD $w / T B I$ groups scored higher on aggression, neuroticism, risk/thrill seeking; and reported more drinks consumed during a drinking episode, more frequent drinking episodes, feeling the need to cut down on drinking, and using more alcohol than intended than the control group. Similarly, the PTSD w/TBI groups scored higher on aggression than the TBI group, higher on neuroticism than the PTSD and TBI groups, and reported more drunk-driving episodes than the control group. The pattern of depression and anxiety was such that the PTSD $w / T B I$ group scored the highest followed by the PTSD group, $T B I$ group, and control group in decreasing order. Both the control and TBI groups scored higher on sociability than the PTSD and PTSD $w / T B I$ groups. The PTSD and PTSD $w / T B I$ groups reported more frequent episodes of speeding (both highway and residential) than the control and TBI groups. Finally, of those who reported smoking, the PTSD group reported smoking more cigarettes per day than the control group.

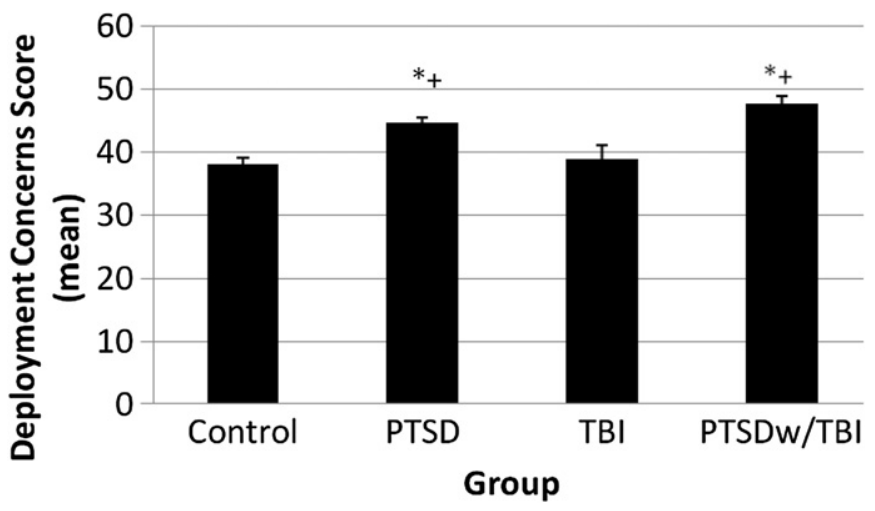

Fig. 2. Bar graph of mean deployment concerns score by group. Error bars represent standard error of the mean. * indicates a significant difference from control group at $p<0.05$. + indicates a significant difference from TBI group at $p<0.05$. 

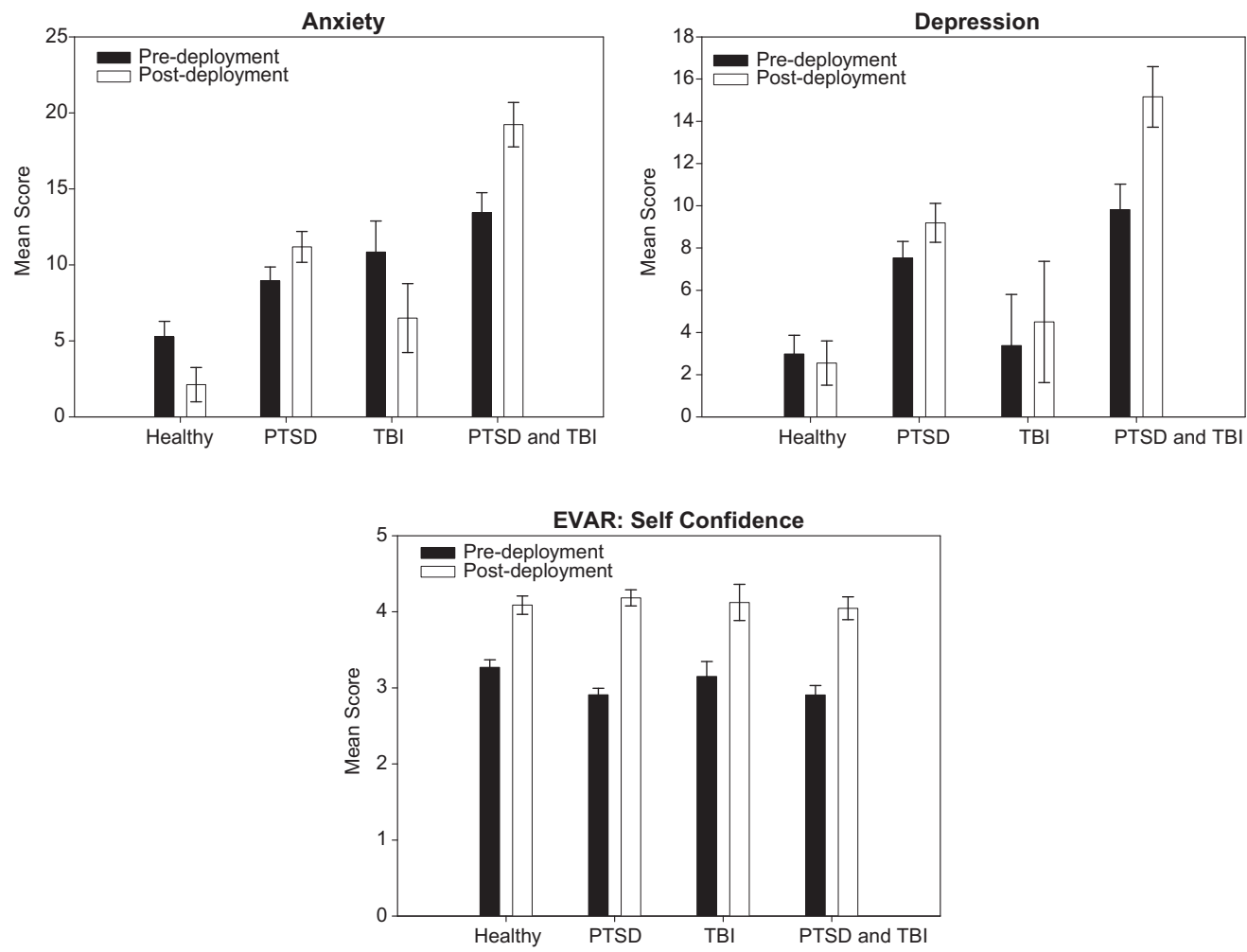

Fig. 3. Bar graphs of interaction effects of combat deployment and group on anxiety, depression, and self-confidence.

All groups showed an increase in self-confidence (i.e., enhanced sense of assuredness and preference for danger), however, the quantity of this increase was greater in the PTSD and PTSD w/TBI groups than the others. The control and TBI groups showed a decrease in anxiety levels post-deployment whereas the PTSD and PTSD $w / T B I$ groups showed an increase. Post-deployment depression symptoms decreased for the control group while increasing for all other groups.

To evaluate the extent to which pre-deployment psychological disturbance (anxiety and depression), combat experiences during deployment, concerns and threat during deployment, and previous combat deployment impacted PTSD score post-deployment, a multiple linear regression was conducted. The model showed that measures of depression pre-deployment and perceived threat during deployment significantly predicted PTSD score and accounted for $32.6 \%$ of the variance, $R^{2}=0.326, F(5,180)=17.383$, $p<0.001$. Specifically, Beck's depression inventory score predeployment, $\beta=0.257, t(185)=3.655, p<0.001$, and deployment concerns score (post-deployment), $\beta=0.341, t(89)=5.267$, $p<0.001$, were significant predictors of PTSD scores. Predeployment anxiety, combat experience, and previous deployment were not significant predictors.

\section{Discussion}

The results of this study strongly suggest that changes in attitudes about risk, risk propensity, and health risk behaviors occur after a combat deployment. Specifically, participants reported increased frequency of alcohol consumption and referrals to ASAP after returning home. Participants who were motorcycle riders reported decreased frequency of helmet use post-deployment. The magnitude of these changes was amplified in participants who screened positive for PTSD. While the statistical significance of the effects of combat deployment, PTSD, and TBI is important, these findings are strengthened by the medium to large effect sizes found as well. The implications of these findings touch a broad range of concerns including public health, return-to-duty and operational readiness, personal safety, and readjustment to life after a deployment.

Participants' responses indicate a greater sense of invincibility and adroitness post-deployment compared to pre-deployment as well as self-confidence. As described by Killgore et al. (2006), the self-confidence factor on the EVAR indicates preference for danger and "being strengthened by hostile situations." Thus, the increases seen in self-confidence may be reflective of an increase in perceptions of one's ability to survive or, rather, one's invincibility. This altered self-perception is understandable, as these Soldiers had recently survived a uniquely dangerous period of life, thus amplifying the perception of their survival abilities and diminishing their perceived susceptibility to negative consequences. These alterations may function as a coping mechanism such that emotional stability is fostered by moving forward from the experience rather than dwelling on the idea that one might not have survived (Bell et al., 2001). Survival is unconsciously attributed to one's exceptional survival skills or invincibility. While this may promote emotional stability and health, the consequence of this altered perception is that a Soldier may engage in dangerous behaviors. Also, there is no indication as to if and when these coping behaviors become a negative habit versus a helpful strategy. The extent to which this altered perception and behaviors serve as an effective coping mechanism is unknown.

Interestingly, participants' personality traits related to risktaking changed across the deployment cycle. Personality was traditionally thought to be relatively stable once adulthood is reached. Recent review shows that personality continues to adapt and develop across adulthood typically in the positive direction (McCrae and Costa, 1994; Roberts and Mroczek, 2008). The results of the current study suggest that aspects of personality may seem 
Table 2

Summary of results of 4 (PTSD, TBI, PTSD w/TBI, control) X 2 (pre-, post-deployment) ANOVAs (ns refers to not significant).

\begin{tabular}{|c|c|c|c|c|c|c|}
\hline Construct & $F$ & df & $p$ & Partial $\eta^{2}$ & Comparison & $p$ \\
\hline \multicolumn{7}{|c|}{ Main effect of combat deployment (pre, post) } \\
\hline Sociability & 6.938 & 1,229 & 0.009 & 0.029 & pre $>$ post & 0.009 \\
\hline Aggression & 9.242 & 1,233 & 0.003 & 0.038 & pre $<$ post & 0.003 \\
\hline Activity & 39.877 & 1,235 & $<0.001$ & 0.145 & pre $<$ post & $<0.001$ \\
\hline Neuroticism & 13.052 & 1,230 & $<0.001$ & 0.054 & pre $<$ post & $<0.001$ \\
\hline IBI: Total invincibility & 48.14 & 1,226 & $<0.001$ & 0.176 & pre $<$ post & $<0.001$ \\
\hline IBI: Adroitness & 106.996 & 1,237 & $<0.001$ & 0.311 & pre $<$ post & $<0.001$ \\
\hline EVAR: Risk/thrill seeking & 22.504 & 1,258 & $<0.001$ & 0.080 & pre $<$ post & $<0.001$ \\
\hline EVAR: Self-confidence & 157.48 & 1,258 & $<0.001$ & 0.379 & pre $<$ post & $<0.001$ \\
\hline EVAR: Need for control & 14.488 & 1,258 & $<0.001$ & 0.053 & pre $>$ post & $<0.001$ \\
\hline Depression & 4.682 & 1,173 & 0.032 & 0.026 & pre $<$ post & 0.032 \\
\hline Frequency of smoking & 4.758 & 1,169 & 0.031 & 0.027 & pre $>$ post & 0.031 \\
\hline Frequency of drinking & 3.946 & 1,250 & 0.048 & 0.016 & pre $<$ post & 0.048 \\
\hline Referred to ASAP & 4.042 & 1,250 & 0.045 & 0.016 & pre $<$ post & 0.045 \\
\hline Motorcycle helmet use & 5.164 & 1,65 & 0.026 & 0.026 & pre $>$ post & 0.026 \\
\hline Impulsive sensation seeking & 0.786 & 1,227 & 0.376 & 0.003 & ns & \\
\hline Cognitive reappraisal & 0.003 & 1,238 & 0.955 & 0.000 & ns & \\
\hline Emotional suppression & 0.043 & 1,241 & 0.836 & 0.000 & ns & \\
\hline IBI: Impunity & 3.545 & 1,241 & 0.061 & 0.014 & ns & \\
\hline IBI: Boldness & 2.523 & 1,232 & 0.114 & 0.011 & ns & \\
\hline Anxiety & 0.024 & 1,245 & 0.878 & 0.000 & ns & \\
\hline \multicolumn{7}{|l|}{ Drunk driving } \\
\hline Cigarettes per day & 0.109 & 1,170 & 0.742 & 0.001 & ns & \\
\hline Alcoholic drinks per day & 3.380 & 1,247 & 0.067 & 0.013 & ns & \\
\hline Frequency of speeding & 0.022 & 1,253 & 0.883 & 0.000 & ns & \\
\hline Drunk driving & 2.860 & 1,245 & 0.092 & 0.012 & ns & \\
\hline Used more alcohol than intended & 0.606 & 1,244 & 0.437 & 0.002 & ns & \\
\hline \multicolumn{7}{|c|}{ Main effect of group (PTSD, TBI, PTSD w/TBI, Control) } \\
\hline \multirow[t]{4}{*}{ Sociability } & 5.932 & 3,229 & 0.001 & 0.072 & control $>$ PTSD & 0.002 \\
\hline & & & & & control $>$ PTSD $w / T B I$ & 0.001 \\
\hline & & & & & $T B I>P T S D$ & 0.034 \\
\hline & & & & & $T B I>P T S D w / T B I$ & 0.009 \\
\hline \multirow[t]{3}{*}{ Aggression } & 6.973 & 3,233 & $<0.001$ & 0.082 & control $<$ PTSD & 0.001 \\
\hline & & & & & control $<$ PTSD $w / T B I$ & $<0.001$ \\
\hline & & & & & $T B I<P T S D w / T B I$ & 0.035 \\
\hline \multirow[t]{4}{*}{ Neuroticism } & 16.594 & 3,230 & $<0.001$ & 0.178 & control $<$ PTSD & $<0.001$ \\
\hline & & & & & control $<$ PTSD $w / T B I$ & $<0.001$ \\
\hline & & & & & $T B I<P T S D w / T B I$ & 0.001 \\
\hline & & & & & $P T S D<P T S D w / T B I$ & 0.019 \\
\hline \multirow[t]{2}{*}{ EVAR: Risk/thrill seeking } & 3.332 & 3,258 & 0.02 & 0.037 & control $<P T S D$ & 0.007 \\
\hline & & & & & control $<$ PTSD $w / T B I$ & 0.008 \\
\hline \multirow[t]{5}{*}{ Anxiety } & 26.735 & 3,245 & $<0.001$ & 0.247 & control $<P T S D$ & $<0.001$ \\
\hline & & & & & control $<$ TBI & 0.012 \\
\hline & & & & & control $<$ PTSD $w / T B I$ & $<0.001$ \\
\hline & & & & & $P T S D<P T S D w / T B I$ & $<0.001$ \\
\hline & & & & & $T B I<P T S D w / T B I$ & $<0.001$ \\
\hline Depression & 19.038 & 3,173 & $<0.001$ & 0.248 & control $<$ PTSD & $<0.001$ \\
\hline & & & & & control $<$ PTSD $w / T B I$ & $<0.001$ \\
\hline & & & & & $P T S D<P T S D w / T B I$ & 0.002 \\
\hline & & & & & $T B I<P T S D w / T B I$ & $<0.001$ \\
\hline Cigarettes per day & 3.029 & 3,170 & 0.031 & 0.051 & control $<$ PTSD & 0.003 \\
\hline Alcoholic drinks per day & 3.392 & 3,247 & 0.019 & 0.096 & control $<P T S D$ & 0.008 \\
\hline & & & & & control $<$ PTSD $w / T B I$ & 0.006 \\
\hline Frequency of speeding & 8.957 & 3,253 & $<0.001$ & 0.092 & control $<$ PTSD & $<0.001$ \\
\hline & & & & & control $<$ PTSD $w / T B I$ & $<0.001$ \\
\hline & & & & & $T B I<P T S D$ & 0.04 \\
\hline & & & & & $T B I<P T S D w / T B I$ & 0.007 \\
\hline Frequency of drinking & 5.03 & 3,250 & 0.002 & 0.057 & control $<$ PTSD & 0.001 \\
\hline & & & & & control $<$ PTSD $w / T B I$ & 0.001 \\
\hline Felt need to cut down drinking & 3.468 & 3,235 & 0.017 & 0.042 & control $<P T S D$ & 0.045 \\
\hline & & & & & control $<$ PTSD $w / T B I$ & 0.002 \\
\hline Drunk driving & 2.667 & 3,245 & 0.048 & 0.032 & control $<$ PTSD $w / T B I$ & 0.01 \\
\hline Used more alcohol than intended & 5.816 & 3,244 & 0.001 & 0.067 & control $<$ PTSD & $<0.001$ \\
\hline & & & & & control $<$ PTSD $w / T B I$ & $<0.001$ \\
\hline Activity & 0.521 & 3,235 & 0.668 & 0.007 & ns & \\
\hline Impulsive sensation seeking & 2.083 & 3,227 & 0.103 & 0.027 & ns & \\
\hline Cognitive reappraisal & 2.268 & 3,238 & 0.081 & 0.028 & ns & \\
\hline Emotional suppression & 1.023 & 3,241 & 0.383 & 0.013 & ns & \\
\hline IBI: Total invincibility & 0.103 & 3,226 & 0.958 & 0.001 & ns & \\
\hline IBI: Adroitness & 0.022 & 3,237 & 0.995 & 0.000 & ns & \\
\hline IBI: Impunity & 0.244 & 3,241 & 0.865 & 0.003 & ns & \\
\hline IBI: Boldness & 0.253 & 3,232 & 0.859 & 0.003 & ns & \\
\hline EVAR: Self-confidence & 0.768 & 3,258 & 0.513 & 0.009 & ns & \\
\hline EVAR: Need for control & 1.055 & 3,258 & 0.369 & 0.012 & ns & \\
\hline
\end{tabular}


Table 2 (continued)

\begin{tabular}{|c|c|c|c|c|c|c|}
\hline Construct & $F$ & $\mathrm{df}$ & $p$ & Partial $\eta^{2}$ & Comparison & $p$ \\
\hline Frequency of smoking & 2.222 & 3,169 & 0.086 & 0.026 & $\mathrm{~ns}$ & \\
\hline Referred to ASAP & 0.584 & 3,250 & 0.626 & 0.007 & ns & \\
\hline Motorcycle helmet use & 0.958 & 3,65 & 0.418 & 0.042 & ns & \\
\hline \multicolumn{7}{|l|}{ Interaction } \\
\hline Anxiety & 8.563 & 3,245 & $<0.001$ & 0.095 & See Fig. 3 & \\
\hline Depression & 3.421 & 3,173 & 0.019 & 0.560 & See Fig. 3 & \\
\hline Self-confidence & 2.655 & 3,258 & 0.049 & 0.030 & See Fig. 3 & \\
\hline Sociability & 2.100 & 3,229 & 0.101 & 0.027 & ns & \\
\hline Aggression & 1.060 & 3,233 & 0.367 & 0.013 & ns & \\
\hline Activity & 1.542 & 3,235 & 0.204 & 0.019 & ns & \\
\hline Neuroticism & 2.585 & 3,230 & 0.054 & 0.033 & ns & \\
\hline Impulsive sensation seeking & 0.054 & 3,227 & 0.983 & 0.001 & ns & \\
\hline Cognitive reappraisal & 0.175 & 3,238 & 0.913 & 0.002 & ns & \\
\hline Emotional suppression & 1.605 & 3,241 & 0.189 & 0.020 & ns & \\
\hline IBI: Total invincibility & 0.830 & 3,226 & 0.479 & 0.011 & ns & \\
\hline IBI: Adroitness & 1.464 & 3,237 & 0.225 & 0.018 & ns & \\
\hline IBI: Impunity & 1.012 & 3,241 & 0.388 & 0.012 & ns & \\
\hline IBI: Boldness & 0.635 & 3,232 & 0.593 & 0.008 & ns & \\
\hline EVAR: Risk/Thrill seeking & 0.720 & 3,258 & 0.541 & 0.008 & ns & \\
\hline EVAR: Need for control & 1.623 & 3,258 & 0.184 & 0.019 & ns & \\
\hline \multicolumn{7}{|l|}{ Drunk driving } \\
\hline Frequency of smoking & 2.392 & 3,169 & 0.069 & 0.028 & ns & \\
\hline Cigarettes per day & 1.327 & 3,170 & 0.267 & 0.023 & ns & \\
\hline Alcoholic drinks per day & 1.918 & 3,247 & 0.127 & 0.023 & ns & \\
\hline Frequency of speeding & 0.732 & 3,253 & 0.534 & 0.009 & ns & \\
\hline Frequency of drinking & 0.677 & 3,250 & 0.567 & 0.008 & ns & \\
\hline Drunk driving & 0.982 & 3,245 & 0.402 & 0.012 & ns & \\
\hline Referred to ASAP & 1.199 & 3,250 & 0.311 & 0.014 & ns & \\
\hline Used more alcohol than intended & 0.929 & 3,244 & 0.427 & 0.011 & ns & \\
\hline Motorcycle helmet use & 0.799 & 3,65 & 0.499 & 0.036 & ns & \\
\hline
\end{tabular}

altered by the life experience of a combat deployment independent of psychological injury. This finding can be summed up as the commonly reported anecdote "you are just not the same" after a deployment. However, the permanence of this "alteration" was not assessed thus making it impossible to interpret whether this change is simply a short-term adaptation effect or if it is long-term.

In our study, Soldiers exhibiting PTSD symptoms were highly susceptible to changes in attitude, perception, and behavior. Those who screened positive for PTSD reported more frequent reckless driving in both residential and built-up areas as well as highway driving. The PTSD and PTSD $w / T B I$ groups also reported more frequent alcohol consumption and quantity consumed during a drinking episode. Of the participants who reported smoking, those with PTSD symptoms smoked more heavily than the healthy participants overall. Drunk driving and feelings of need to cut down on alcohol consumption were also reported as occurring more frequently post-deployment in the PTSD and PTSD $w / T B I$ groups. While health risk behaviors increased post-deployment regardless of TBI or PTSD, the range of behaviors and frequency of behaviors reported overall were exaggerated in those screened positive for PTSD.

Personality dimensions related to sociability, aggression, and neuroticism differed between groups such that PTSD and PTSD w/TBI groups were less sociable, more aggressive, and more neurotic than the control and TBI groups. These differences did not interact with phase of testing (pre- versus post-deployment) suggesting that personality may play a role in resilience to PTSD. Anxiety and depression decreased post-deployment for healthy participants whereas these variables increased for those who screened positive for PTSD. For all Soldiers, pre-deployment is a stressful time where tight training schedules demand one's time as well as preparation for the family left behind (e.g., finances, wills, childcare, thoughts of injury or death). For those who return relatively healthy, postdeployment is a time of relief (e.g., reconnecting with family and friends, familiarity and predictability, feelings of safety and security) which is not the case for those experiencing psychological problems.

\subsection{Practical implications}

Engaging in risky behaviors such as alcohol use and smoking puts not only individual health and safety in jeopardy, but also family safety and public health. The findings of this study expand beyond health risk behaviors and suggest that perception of risks and attitudes about invincibility are altered after a combat deployment. This skewed perception of risk endangers more aspects of a Soldier's life than off-duty health and safety-operational readiness is another area of a Soldier's life that is potentially open for hazardous consequences. If a Soldier engages in risky behavior while still in a combat environment, consequences could be fatal; once redeployed and returned-to-duty, military operations may be compromised due to a Soldier's disproportionate view of risk. However, the permanence of this skewed perception is still unknown and further research is needed to address this topic.

\subsection{Study limitations and future research}

While the results of this study provide a characterization of the pattern of health risk behaviors and attitudes about risk across the deployment cycle as well as illuminating differences in behaviors and attitudes between those who screened positive for PTSD and/or TBI and those who did not, there are limitations that should be considered when interpreting these data. First, given the nature of a quasi-experimental study, PTSD and TBI were not randomly assigned and thus resulted in unequal sample sizes. Since unequal sample size lends to a violation of the assumption of homogeneity, a statistical test of the assumption supported the robustness of the findings. Secondly, the only injury information collected was related to PTSD and TBI whereas the experience of sustaining other 
injuries during deployment may have also influenced participants' responses. Third, the groups were categorized based on a selfreport screening tool which is far less sophisticated than the standard methods applied for diagnosing PTSD and TBI. The significant results obtained despite this crude method of assessment, however, lend strength to the findings. Fourth, some participants were unavailable for testing post-deployment due to behavioral problems or medical evacuation prior to the testing window; these untested subgroups could exhibit different patterns of post-deployment risk-taking behavior. Also, participants were allowed to skip questions they did not feel comfortable answering. These factors lend to concerns of differential attrition. Finally, the sample studied was not a random sample of Soldiers but rather a convenience sample which poses a threat to the external validity of these results. To address this limitation, the representativeness of the sample was presented.

Whereas this study contributes to the understanding of changes in risk attitudes by documenting the pattern of engagement in risky behavior across the deployment cycle, much work is yet to be done. Specifically, the time course of these changes is unknown. A longitudinal assessment extending at a least a year after redeployment would shed light on the longevity of this problem. Likewise, a more controlled and sophisticated investigation into the impact of PTSD, with and without a history of TBI, on risk attitudes and health risk behaviors is needed to develop causal inferences about the relationship between PTSD and risk-taking. Studies are currently underway to model the predictive value of individual differences (e.g., personality, emotion regulation, combat experiences, deployment concerns) on risk attitudes and risk behaviors.

\section{Conclusions}

The results of this longitudinal study support previous anecdotal and between-subjects evidence suggesting that Soldiers are more likely to engage in risky behaviors post-deployment compared to pre-deployment. Changes were evident in all groups of Soldiers, but were most pronounced in those screening positive for PTSD (with or without TBI).

\section{Role of funding source}

This project was funded by the Medical Research and Material Command under program element numbers 633002.800C5 and $622787.869 \mathrm{P} 1$. The funding source had no further role in study and statistical design, data collection, analysis, interpretation of findings, or writing of the report.

\section{Contributors}

Amanda M. Kelley was primarily responsible for the design of the study and selection of measures, conducting literature searches, the development and conception of hypotheses, the supervision of data collections, conducting the statistical analyses, and writing the manuscript.

Jeremy R. Athy was primarily responsible for the data coding, ensuring quality control of the data, and calculating survey scores. He assisted in development of the design and selection of measures. In addition, he assisted in the data collections, interpretation of the results and editing of the manuscript.

Timothy $\mathrm{H}$. Cho assisted in the interpretation of the results and made substantial contributions to preparation of the manuscript.

Bradley Erickson was primarily responsible for the coordination of the data collection and assisted in the selection of measures, data collections, data organization, interpretation of the results, and editing of the manuscript.
Melody King assisted in the selection of measures, data collections, data organization, and interpretation of the results.

Pedro Cruz assisted in the data collections, data organization, and interpretation of the results.

\section{Conflict of interest}

None of the authors declare any potential or actual conflict of interest.

\section{Acknowledgments}

The views expressed in this article are those of the authors and do not reflect the official policy or position of the Department of the Army, the Department of Defense, the U.S. government, or the institution affiliated with the authors. The authors wish to thank LTC Richard Coffman, MAJ Michael Kovacevic, MAJ Jeremy Smith, CPT William Fehrenbach, and CPT Bruce Erickson for their support of this study. The authors also wish to thank Lori St. Onge, Ph.D. COL Dana Renta, John S. Crowley, M.D., and Art Estrada, Ph.D. for edits on earlier versions of this paper and to Mrs. Jean Southwell and Mr. Scott Seggerman for their assistance with the Defense Medical Surveillance System. Finally, the authors wish to thank all the service members who participated in this study for their service.

\section{References}

Bechara A, Damasio H, Tranel D, Damasio AR. Deciding advantageously before knowing the advantageous strategy. Science 1997;275:1293-5.

Bechara A, Dolan S, Denburg N, Hindes A, Anderson SW, Nathan PE. Decisionmaking deficits, linked to a dysfunctional ventromedial prefrontal cortex, revealed in alcohol and stimulant abusers. Neuropsychologia 2001;39:376-89.

Bechara A, Tranel D, Damasio H. Characterization of the decision-making deficit of patients with ventromedial prefrontal cortex lesions. Brain 2000;123: 2189-202.

Beck AT, Epstein N, Brown G, Steer RA. An inventory for measuring clinical anxiety: psychometric properties. Journal of Consulting and Clinical Psychology 1988a; 56:893-7.

Beck AT, Steer RA. Internal consistencies of the original and revised Beck depression inventory. Journal of Clinical Psychology 1984;40:1365-7.

Beck AT, Steer RA, Garbin GM. Psychometric properties of the Beck Depression Inventory: twenty-five years of evaluation. Clinical Psychology Review 1988b;8: 77-100.

Bell NS, Amoroso PJ, Wegman DH, Senier L. Proposed explanations for excess injury among veterans of the Persian Gulf War and a call for greater attention from policymakers and researchers. Injury Prevention 2001;7:4-9.

Bliese PD, Wright KM, Adler AB, Cabrera O, Castro CA, Hoge CW. Validating the PC-PTSD and the PTSD checklist with soldiers returning from combat. Journal of Consulting and Clinical Psychology 2008;76:272-81.

Byrnes JP. The development of self-regulated decision making. In: Jacobs JE Klaczynski PA, editors. The development of judgment and decision making in children and adolescents. Mahwah, NJ: Lawrence Erlbaum Associates; 2005.

Centers for Disease Control and Prevention. Youth behavior risk survey [accessed 23.07.09], http://www.cdc.gov/yrbss; 2009.

Gross JJ, John OP. Individual differences in two emotion regulation processes: implications for affect, relationships, and well-being. Journal of Personality and Social Psychology 2003;85:348-62.

Hewitt PL, Norton GR. The Beck anxiety inventory: a psychometric analysis Psychological Assessment 1993;5:408-12.

Hoge CW, Castro CA, Messer SC, McGurk D, Cotting DI, Koffman RL. Combat duty in Iraq and Afghanistan, mental health problems, and barriers to care. New England Journal of Medicine 2004;351:13-22.

Kang HK, Natelson BH, Mahan CM, Lee KY, Murphy FM. Post-traumatic stress disorder and chronic fatigue syndrome-like illness among Gulf War veterans: a population-based survey of 30,000 veterans. American Journal of Epidemiology 2003;157:141-8.

Keane T, Fairbank J, Caddell J, Zimering R, Taylor K, Mora C. Clinical evaluation of a measure to assess combat exposure. Psychological Assessment 1989;1:53-5

Killgore WDS, Cotting DI, Thomas JL, Cox AL, McGurk D, Vo AH, et al. Post-combat invincibility: violent combat experiences are associated with increased risktaking propensity following deployment. Journal of Psychiatric Research 2008;42:58-63.

Killgore WDS, Kelley AM, Balkin T. So you think you're bulletproof: development and validation of the Invincibility Belief Index (IBI). Military Medicine 2010;175: 499-508. 
Killgore WDS, Vo AH, Castro CA, Hoge CW. Assessing risk propensity in American soldiers: preliminary reliability and validity of the Evaluation of Risks (EVAR) Scale - English version. Military Medicine 2006;171:233-9.

King DW, King LA, Vogt DS. Manual for the Deployment Risk and Resilience Inventory (DRRI): a collection of scales for studying deployment-related experiences in military veterans. Boston, MA: National Center for PTSD; 2003.

King LA, King DW, Vogt DS, Knight J, Samper R. Deployment risk and reslience inventory: a collection of measures for studying deployment-related experiences in military personnel and veterans. Military Psychology 2006;18: 89-120.

Lejuez CW, Read JP, Kahler CW, Richards JB, Ramsey SE, Stuart GL, et al. Evaluation of a behavioral measure of risk taking: the Balloon Analogue Risk Task (BART). Journal of Experimental Psychology: Applied 2002;8:75-84.

McCrae RR, Costa PT. The stability of personality: observation and evaluations. Current Directions in Psychological Science 1994;3:173-5.

Molina ME, Isoardi R, Prado MN, Beltolila S. Basal cerebral glucose distribution in long-term post-traumatic stress disorder. World Journal of Biological Psychiatry 2007; $13: 1-9$

O’Jile JR, Ryan LM, Parks-Levy J, Betz B, Gouvier WD. Sensation seeking and risk behaviors in young adults with and without a history of head injury. Applied Neuropsychology 2004;11:107-12.

Parker D, Reason JT, Manstead ASR, Stradling S. Driving errors, driving violations and accident involvement. Ergonomics 1995;38:1036-48.

Roberts BE, Mroczek DK. Personality trait stability and change. Current Directions in Psychological Science 2008;17:31-5.

Ruberton MV, Brundage JF. The Defense Medical Surveillance System and the Department of Defense serum repository: glimpses of the future of public health surveillance. American Journal of Public Health 2002;92:1900-4.
Saunders JB, Aasland OG, Babor TF, de la Fuente JR, Grant M. Development of the alcohol use disorders identification test (AUDIT): WHO collaborative project on early detection of persona with harmful alcohol consumption. Addiction 1993; 88:791-803

Schneiderman AI, Braver ER, Kang HK. Understanding sequelae of injury mechanisms and mild traumatic brain injury incurred during the conflicts of Iraq and Afghanistant: persistent postconcussive symptoms and posttraumatic stress disorder. American Journal of Epidemiology 2008;15:1446-52.

Schwab KA, Ivins B, Cramer G, Johnson W, Sluss-Tiller M, Kiley K, et al. Screening for traumatic brain injury in troops returning from deployment in Afghanistan and Iraq: initial investigation of the usefulness of a short screening tool for traumatic brain injury. Journal of Head Trauma Rehabilitation 2007;22: 377-89.

Sharkansky EJ, King DW, King LA, Wolfe J, Erickson DJ, Stokes LR. Coping with Gulf War combat stress: mediating and moderating effects. Journal of Abnormal Psychology 2000;109:188-97.

Sicard B, Jouve E, Blin O. Risk propensity assessment in military special operations. Military Medicine 2001;166:871-4.

Tanielian T, Jaycox LH. Invisible wounds of war: psychological and cognitive injuries, their consequences, and services to assist recovery. Santa Monica, Calif.: RAND Corporation; 2008.

Thomsen CJ, Stander VA, McWhorter SK, Rabenhorst MM, Milner JS. Effects of combat deployment on risky and self-destructive behavior among active duty military personnel. Journal of Psychiatric Research 2011;45:1321-31.

Zuckerman M, Kuhlman DM. Personality and risk-taking: common biosocial factors. Journal of Personality 2000;68:999-1029.

Zuckerman M, Kuhlman DM, Joireman J, Teta P, Kraft M. A comparison of three structural models for personality: the big three, the big five, and the alternative five. Journal of Personality and Social Psychology 1993;65:757-68. 